UNDERGROUND MINING ENGINEERING 33 (2018) 17-30 UDK 62

\title{
3D MODELING OF TERRAIN AND SPATIAL VISUALIZATION OF UNDERGROUND FACILITIES AT THE "CRVENI BREG" MINE
}

\author{
Luka Crnogorac ${ }^{1}$, Zoran Gojković1, Aleksandar Milutinović ${ }^{1}$, Aleksandar Ganić ${ }^{1}$ \\ and Rade Tokalić ${ }^{1}$
}

Received: October 7, 2018

Accepted: November 21, 2018

\begin{abstract}
This paper presents the process of making the 3D model of terrain, digital elevation model and orthophoto at the location of the "Crveni Breg" mine. The necessary photos were taken with a 20-megapixel digital camera attached on the DJI Phantom 4 Pro photography UAV. AgiSoft PhotoScan was used to create the 3D model of terrain. A spatial visualization of mining facilities on the second horizon of the "Crveni Breg" mine was carried out with the assistance of this 3D model of the underground facilities designed in the Autodesk Civil 3D software. Two 3D models were connected to obtain complete spatial visualization of the area.

The aim of this paper is to present a general overview of the possibilities that emerge by combining digital aerial photogrammetry and 3D models of underground mines, primarily in the context of protecting infrastructure, and other objects from the impact of underground mining operations as well as serving as a quick, simple, easy and relatively reliable track for potential subsidence.
\end{abstract}

Keywords: digital aerial photogrammetry; unmanned aerial vehicle (UAV); 3D modeling; underground facilities; object protection;

\section{INTRODUCTION}

Mining graphic documentation provides complete information on situations related to terrain surface and on mining work within a particular exploitation field. One of the most economical and effective ways to get up-to-date cartographic data is through a digital orthophoto (Ganić, 2011). As classical aerial photogrammetry is quite time consuming and rather cost ineffective, the relatively affordable prices of an unmanned aerial vehicle (UAV) have contributed to its widespread use and application in orthophoto making.

Photogrammetry can be defined as a set of techniques used for physical measurements from 2D images, while digital photogrammetry is any kind of photogrammetry based on

\footnotetext{
${ }^{1}$ University of Belgrade - Faculty of Mining and Geology, Belgrade, Serbia Emails: luka.crnogorac@ rgf.bg.ac.rs; zoran.gojkovic@ rgf.bg.ac.rs; aleksandar.milutinovic@ @rgf.bg.ac.rs; aleksandar.ganic@ @rgf.bg.ac.rs; rade.tokalic@ rgf.bg.ac.rs
} 
digital photographs (Chen \& Clark, 2016; Mikhail et al., 2001). With photogrammetry it is therefore possible to perform 3D physical measurements based on 2D images.

UAVs in the mining industry have the widest use and application in the photo shooting of open-pit mines, quarries and their slopes, and are used to gather data for making 3D terrain models. Based on such models, it is possible to monitor the process of extraction of mineral resources and potential landslides as well as determine the volumes of materials. Authors G. Vassen and A. Clerici (2018), Cohen et al. (2017) and Wen Yan Tung et al. (2018) dealt with the aforementioned issues. In his paper on the achievements in photogrammetry using a UAV, M. Gerke (2018) emphasizes the importance of accessibility -being able to easily obtain current data and high-quality georeferenced photographs (orthophoto), point cloud and altitude models at any time.

On the other hand, the application of digital photogrammetry, in the underground exploitation of mineral resources and underground construction, has been mainly reduced to defining the parameters of the face of the work site. Certainly, the use of UAVs in underground facilities is extremely limited but in the design stage of the mine, it can be useful with the help of UAVs and the 3D modeling of the terrain the dimensions can be measured and a display of the protective pillars, as well as their impact on the underground premises (i.e. preparation and excavation of underground facilities) can be provided. Moreover, by using UAVs, it is easy to track the terrain displacements during the exploitation of the deposit which saves a significant amount of time and money invested in the process.

\section{SITE MAPPING}

\subsection{Area of interest}

The area of interest is the school mine "Crveni Breg" on Avala, located in the municipality of Vozdovac, which belongs to the city of Belgrade. The Municipality of Vozdovac covers an area of 14,864 ha (http://vozdovac.rs/opsti-podaci/) while the filming area at the "Crveni Breg" mine covers an area of 13 ha. The satellite image of the "Crveni Breg" mine is shown in Figure 1. The reference points that will be used for georeferencing are defined by the space coordinates in the UTM coordinate system (WGS 84 / UTM zone 34N) (Table 1). 


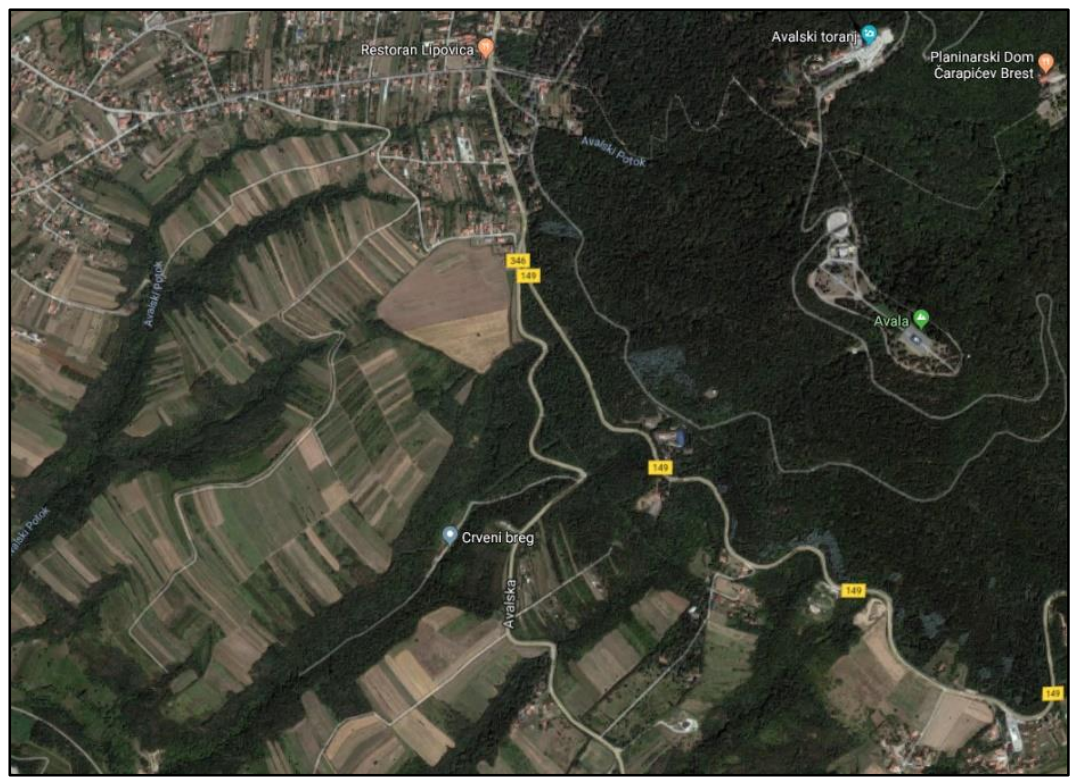

Figure 1 Satellite image of the mine "Crveni Breg” (Google maps, 2018)

Table 1 Spatial coordinates of reference points

\begin{tabular}{cccc}
\hline Point marker & Easting $(\mathrm{m})$ & Northing $(\mathrm{m})$ & Altitude $(\mathrm{m})$ \\
\hline 1 & 460641.589 & 4948030.686 & 236.767 \\
2 & 460576.813 & 4947773.339 & 225.778 \\
P101 & 460436.86 & 4948054.033 & 200.396 \\
P102 & 460413.88 & 4947952.788 & 186.300 \\
P103 & 460390.722 & 4947966.783 & 192.677 \\
P104 & 460347.595 & 4947877.318 & 184.854 \\
\hline
\end{tabular}

$\mathrm{Pb}$ and $\mathrm{Zn}$ mine "Crveni Breg" operated actively, with some suspensions, from 1886. to 1953. when it was close. In 1954. the right to use it was given to Faculty of Mining and Geology and since than it is used for educational and touristic purposes. More information about mining activities at "Crveni Breg" mine was published in paper „Mining activities through history at Avala locality” by L. Crnogorac (2016).

The AgiSoft PhotoScan software (http://www.agisoft.com/) was used to create the 3D terrain model, digital elevation model (DEM) and orthophoto. This software is presented as one of the leaders in the market. AgiSoft PhotoScan makes it possible to work with two-dimensional images, as well as process them, which is necessary for the design and reconstruction of a point cloud. 


\subsection{UAV DJI Phantom 4 Pro}

The recording was performed by a UAV DJI Phantom 4 Pro (shown on Figure 2). It is a quadcopter with a $350 \mathrm{~mm}$ magnesium frame (without propellers), whose mass -with battery and propellers- is $1388 \mathrm{~g}$. In action mode, the aircraft reaches a maximum speed of $72 \mathrm{~km} / \mathrm{h}$, with a maximum speed of $6 \mathrm{~km} / \mathrm{h}$ and a maximum dip speed of $4 \mathrm{~km} / \mathrm{h}$. The ceiling of the flight is $6000 \mathrm{~m}$ above sea level. The aircraft uses a LiPo $4 \mathrm{~S}$ battery with the capacity for $5870 \mathrm{mAh}$ which provides up to $30 \mathrm{~min}$ of flight autonomy footage. The system of flight autonomy has double-rear sensors for visual positioning and infrared sensors to track obstacles in five directions and avoid them in four directions.

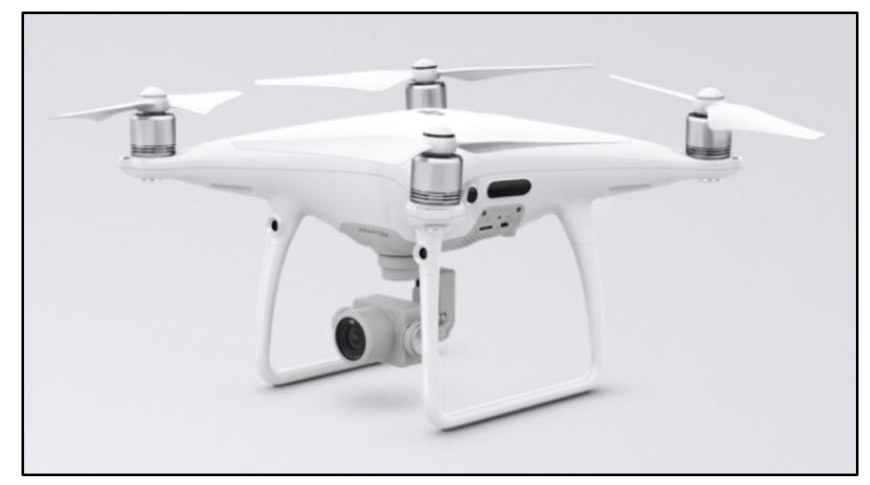

Figure 2 DJI Phantom 4 Pro (Fiveadventures, 2016)

The most important part of the aircraft is the sensor. The camera on this aircraft uses a 1-inch CMOS sensor of 20 megapixels. The camera's optics consist of eight elements arranged in seven groups (shown on Figure 3). The camera is wide angle, with a focal length of $8.8 \mathrm{~mm} / 24 \mathrm{~mm}$. The opening of the camera's aperture is in the range of $\mathrm{f} 2.8$ to $\mathrm{f} 11$, with a shutter speed of up to $1 / 2000 \mathrm{~s}$ (electronic shutter up to $1 / 8000 \mathrm{~s}$ ). The maximum ISO is 6400 for videos, or 12800 for photos, and a resolution of 4096 pixels x 2160 pixels.

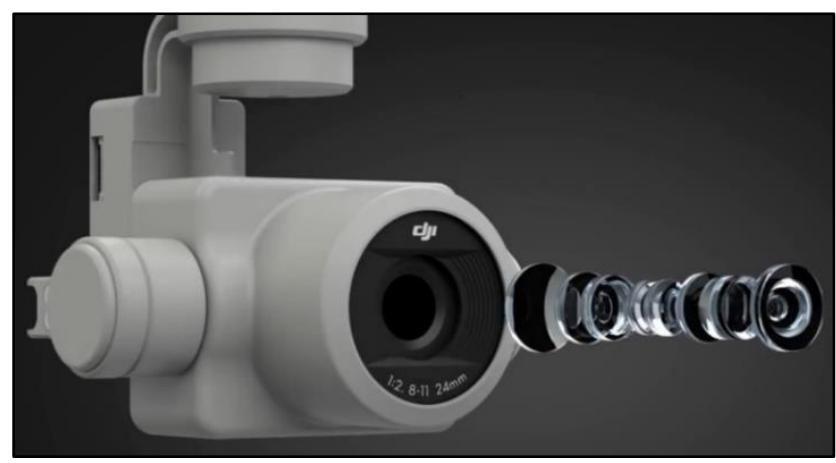

Figure 3 Optics of the camera on the DJI Phantom 4 Pro (Sz dhu technology co. Itd., 2018) 
The operating frequency of the remote controller is $2.4 \mathrm{GHz}$ and $5.8 \mathrm{GHz}$, which ensures greater flight safety, as well as an uninhibited range of information transfer up to $7 \mathrm{~km}$ (i.e. without obstacles or disturbances) (Rcshop, 2016).

\subsection{Flight plan}

Unmanned aerial vehicles (UAVs) are classified as:

- UAVs used for commercial purposes;

- UAVs used for non-commercial purposes (aeronautical models and unmanned aerials used for scientific, educational and other purposes).

According to operating mass and performance (maximum flight altitude, flight speed and range), UAVs are classified into four categories. Regardless of the category of aircraft, the flight plan at a particular location must comply with the Rulebook on Unmanned Aircraft (Official Gazette of the Republic of Serbia, 2015) issued by the Civil Aviation Directorate of the Republic of Serbia and based on the Air Transport Act.

The flight of an UAV takes place only in the allocated part of the airspace, which is decided upon by the unit for civil-military co-ordination within the framework of the air traffic controls of Serbia and Montenegro.

It is prohibited to fly UAVs in an airspace spanning up to $5 \mathrm{~km}$ from the aerodrome reference point located in Class D of the airspace, unless the Civil Aviation Directorate of the Republic of Serbia has approved it. At a distance of more than $5 \mathrm{~km}$ from the aerodrome, in reference to air-class $\mathrm{D}$, flight of UAVs is allowed at a height of up to 30 $\mathrm{m}$ above ground.

The part of the airspace in which UAVs are allowed to fly is known as the flight zone and-depending on the construction and population of the area above which the flight is performed- the following are distinguished:

- region I - non-built and uninhabited area in which there are no people, except for persons who operate an UAV;

- region II - built, but uninhabited, area in which there are construction objects unintended for occupancy, in which the occasional shorter retention of people is possible;

- region III - inhabited area, in which there are buildings intended for permanent living and people's occupancy;

- region IV - all densely-populated, urban or central urban areas where many people gather. 
All UAVs can be used in regions I and II, while UAVs used for commercial purposes may also be used in regions III and IV, along with the prior approval of the Civil Aviation Directorate of the Republic of Serbia (http://cad.gov.rs/).

A person operating a UAV for commercial purposes, as well as a person who operates a UAV of categories 2, 3 and 4, may only be an adult (i.e. persons 18+) who fits the health and knowledge criteria required in accordance to aeronautical regulations.

A UAV can only be flown by day, whereby it must always be in the visible field of the person handling it.

The maximum allowed flight height of a UAV is $100 \mathrm{~m}$ above ground, unless the Directorate approves a flight at a higher altitude.

The maximum allowed horizontal distance of a UAV from a person operating it is $500 \mathrm{~m}$.

It is prohibited to use UAVs at a horizontal distance of less than $500 \mathrm{~m}$ from significant infrastructure and other facilities (power plants, electrical high voltage installations, state institutions, military facilities, water treatment plants, highways, correctional facilities, etc.) unless permitted by the owner or user of the facility.

Moreover, a person operating an UAV is obliged to maintain a safe horizontal distance from people (i.e. not less than $30 \mathrm{~m}$ ).

The flight plan above the "Crveni Breg" school mine on Avala, in accordance with the rulebook on Unmanned Aircraft, was made with the DroneDeploy software. The recording area was 13 ha. The specified flight height was $80 \mathrm{~m}$ above the ground (above the point of departure). To create an orthophoto area, the size of the longitudinal and transverse photo switching is set at $80 \%$. Based on these parameters, a flight plan -with a flight duration of eight minutes- was created and on that occasion, 231 photos of the area under the aircraft were taken.

\section{3D MODEL DESIGN}

\subsection{D Modeling of terrain}

A 3D model of terrain, a DEM and an orthophoto were constructed based on the 231 photos taken with the UAV DJI Phantom 4 Pro camera and AgiSoft PhotoScan software. The process of creating a model itself consisted, in short, of the following steps:

1. Uploading and checking image quality

2. Aligning the image and creating a rare point cloud

3. Creating a dense point cloud

4. Creating a 3D terrain model based on dense point cloud

5. Creating a digital elevation model (DEM) based on a dense point cloud in the corresponding coordinate system

6. Creating an orthophoto based on the digital elevation model (DEM) 
After 3D terrain modeling, with AutoDesk Civil 3D 2019 software (https://www.autodesk.com/products/civil-3d/overview) and based on known polygon points coordinates on the second horizon of the "Crveni Breg" mine, two models (of the terrain and underground facilities) were merged. Polygon points in the "Crveni Breg" mine are defined in the old state coordinate system of the Republic of Serbia (GausKriger's coordinate system). To unify the terrain and underground facilities models, it was necessary to carry out the transformation of the coordinates of the polygon points of the traverse from the Gaus-Kriger coordinate system in UTM (Gojković et al., 2017).

AgiSoft PhotoScan allows you to import different image formats (TIFF, BMP, PNG, JPG, etc ...). A total of 231 photos taken during the flight (in JPG format) were imported into the program.

The reference points on the terrain are first appropriately marked and then recognized in the photos and finally their spatial coordinates are attached in the software. In Figure 4, a marker (reference point P1) is displayed on one of the photos.

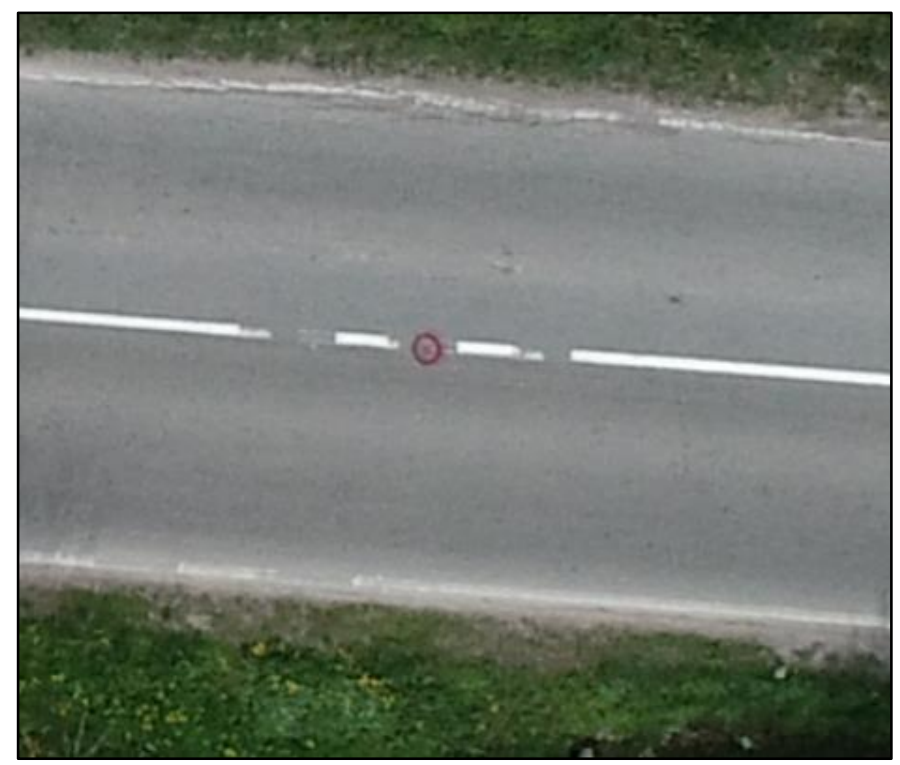

Figure 4 Marker (reference point P1) marked with red circle

After marking the same reference point in two different photos, the program automatically recognizes it in all other photos. After entering all reference points (markers), their coordinates are included in the program. When entering the document, the appropriate coordinate system is selected -in this case, the WGS84 / UTM zone 34N.

The result of the leveling is the defined position of the camera as well as the elements of the external orientation (reference points or markers). After the recorded and processed 
recordings, the process of equalization was completed through the Align Photos command, where it was given a window frame for defining the equalization parameters. The highest level of accuracy is then selected.

After this process, a rare point cloud is obtained where, by selecting the Show Cameras option within the model section, one can see the reconstructed camera positions. Defined points can be seen by selecting the point cloud command on the work window. Figure 5 shows the position of the camera.

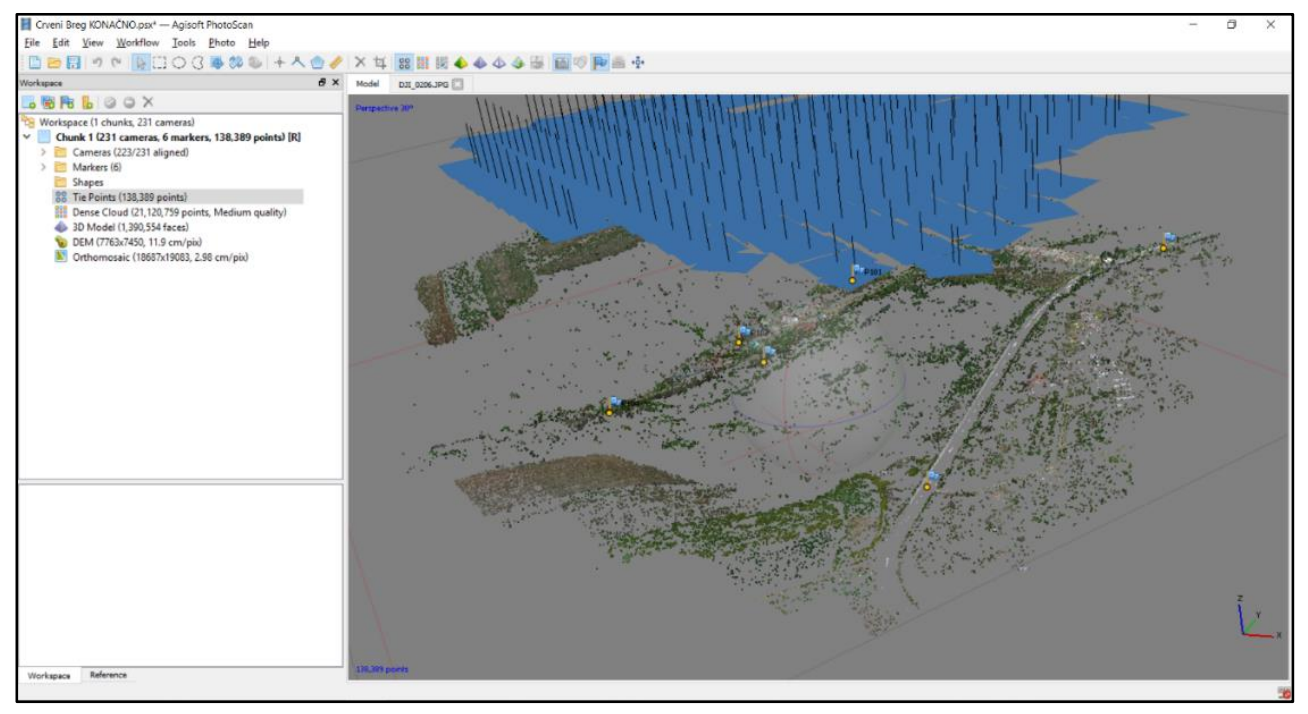

Figure 5 Display of camera position and rare point cloud

After the previous process, it is necessary to optimize the camera parameters to correct a rare point cloud. In this procedure, it includes the removal of all the points in a rare cloud in order to eliminate any visibly misjudged positions. Optimization can be initiated based on the footage and reference points (markers) given that better results are achieved with the markers option.

The result of the previous operations is a rare point cloud of 138,389 points. Generating a dense point cloud is necessary to obtain the basis for the 3D model of terrain, digital elevation model (DEM) and orthophoto.

When generating a dense point cloud, it is necessary to define the following parameters of a dense point cloud: quality and depth filtering.

For the creation of a dense point cloud consisting of 21120759 dots, the computer required about eight hours of data processing.

A tiled model is a digital terrain model in which each node has its own height and color and allows for more significant $3 \mathrm{D}$ visualization. It is necessary to define the size of the pixel and the size of the tile. In this case, a pixel size of $0.0298482 \mathrm{~m}$ and a tile size of 
256 was adopted, which is the default parameter defined by the program. The obtained terrain model is shown in Figure 6.

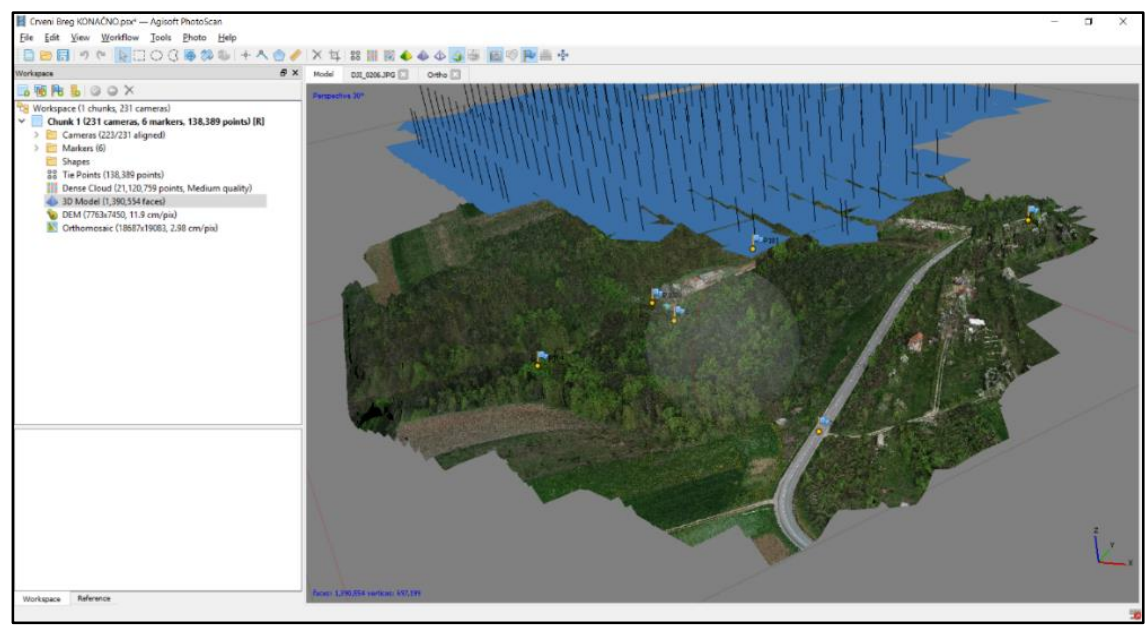

Figure $63 \mathrm{D}$ terrain model with camera positions

The digital elevation model (DEM) is constructed based on a defined dense cloud point. DEM represents one of the ways of presenting the surface of the terrain. Defined models are created based on known positions and height of points as well as characteristic points of the terrain (turning and structural lines). When creating a DEM, it is necessary to define several parameters. Source data implies whether a DEM will be defined based on a rare or dense point cloud. In this paper, the data source was a dense point cloud and for mathematical representation of the terrain, the default interpolation was selected. Figure 7 gives an overview of the obtained digital elevation model based on the entered parameters.

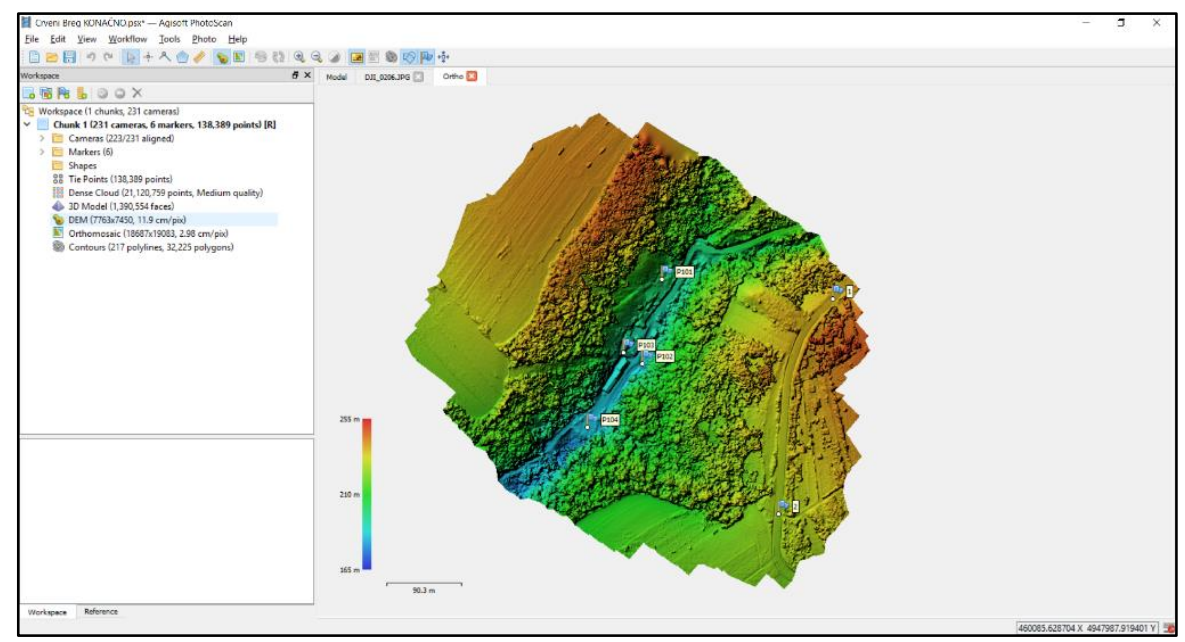

Figure 7 Display of the digital elevation model (DEM) 
A digital orthophoto image is an aerial photogrammetric image of a part of the earth's surface in digital form, subjected to digital orthorectification, in order to eliminate the effects of the central projection, the inclination of the camera axis and the relief of the terrain. The quality of digital orthophoto products depends directly on the quality of the digital image and its geometric and radiometric characteristics, i.e. the quality of the performed rectification.

The software generates an orthophoto using the Build Orthomosaic function, after defining the required parameters: surface, blending mode, region, and pixel size. As a digital surface in operation, DEM was used while the pixel size was $2.98369 \mathrm{~cm}$. Figure 8 shows an orthophoto view.

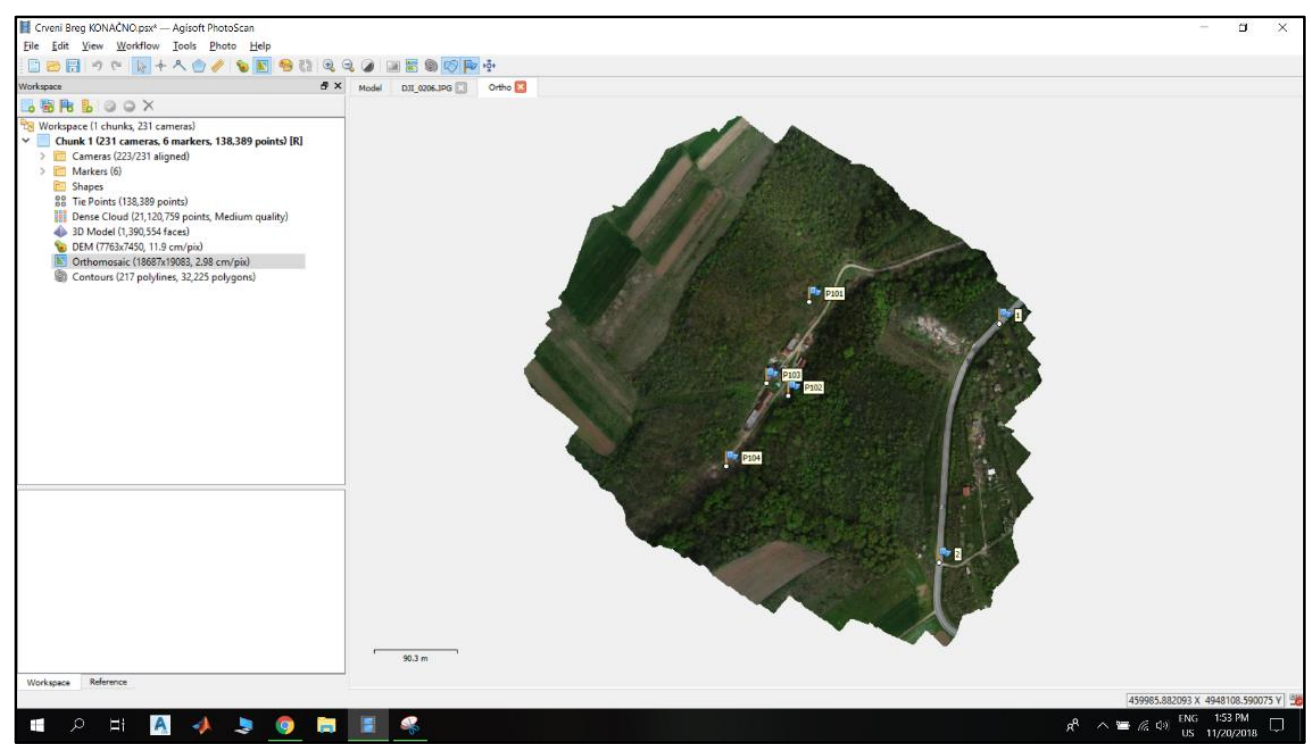

Figure 8 Digital orthophoto of the terrain

AgiSoft PhotoScan has algorithms for calculating distance, surface measurements and volumes on an orthophoto.

Through the export command of the generated digital orthophoto, it is possible to export data in multiple formats. In addition to orthophoto, the program provides the possibility of exporting contour lines, DEMs, clouds of clouds, as well as 3D models, into appropriate formats. The 3D terrain model is exported in a format customized for further work in AutoCAD and other similar programs. 


\subsection{D Modeling of underground facilities}

A 3D model of underground facilities on the second horizon of the "Crveni Breg" mine was created in the Civil 3D program. Based on the coordinates and angles of the polygon points of the traverse, with the generalization of the dimensions of the cross-section of the adit (height and width $2 \mathrm{~m}$, with a low-arch cross-sectional shape), a 3D body was made. It also defined and presented the haulage chamber and shaft (connection with the third horizon of the mine).

3D model of terrain and underground facilities is shown in Figure 9.

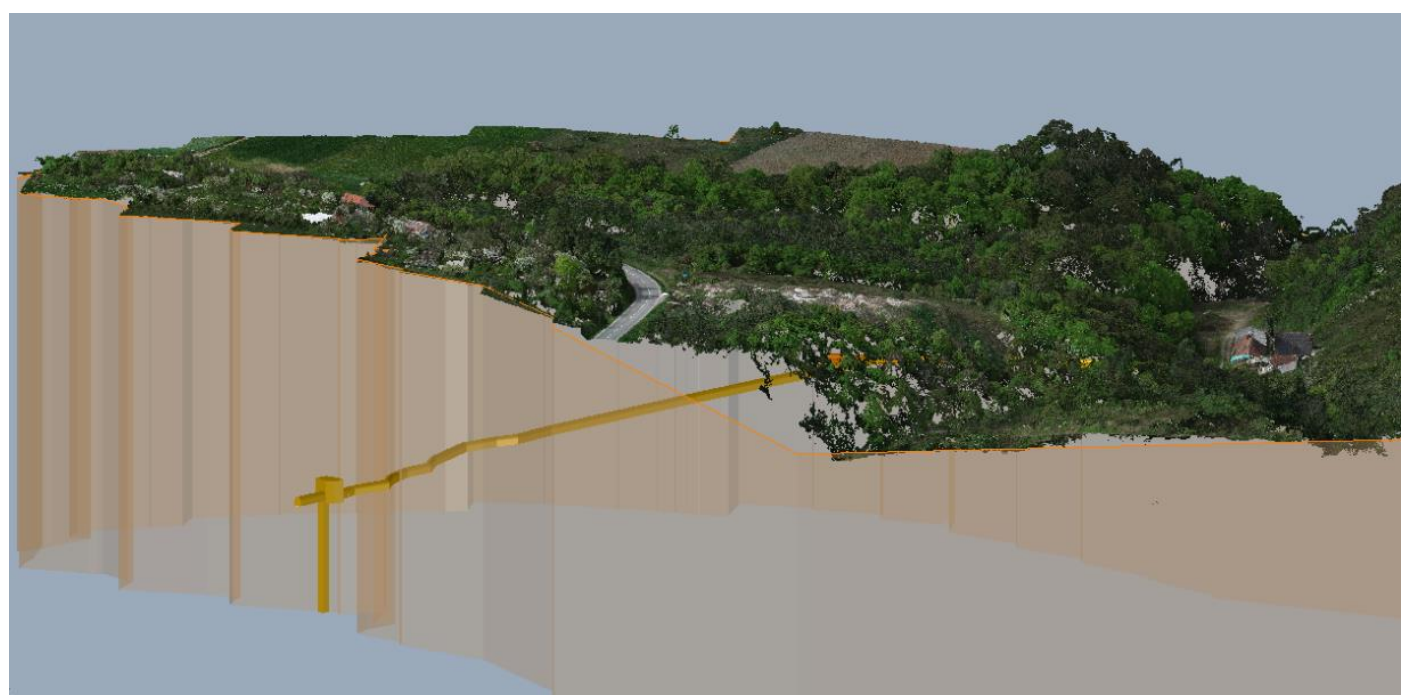

Figure 9 3D terrain display with underground facilities

Figure 10 shows the top view, located near the adit, from which the infrastructural objects on the surface of the terrain are shown. That is, generally speaking, the zone that is influenced by underground mining-based operations. Furthermore, a combination of 3D terrain and underground facilities models can perfectly serve as a very obvious overview of all natural and artificial objects on the surface of the terrain that are in the zone of influence of these underground mining operations -whose deformations can present a direct or indirect danger to the safety of miners within the mine, as well as the population on the surface of the terrain. 


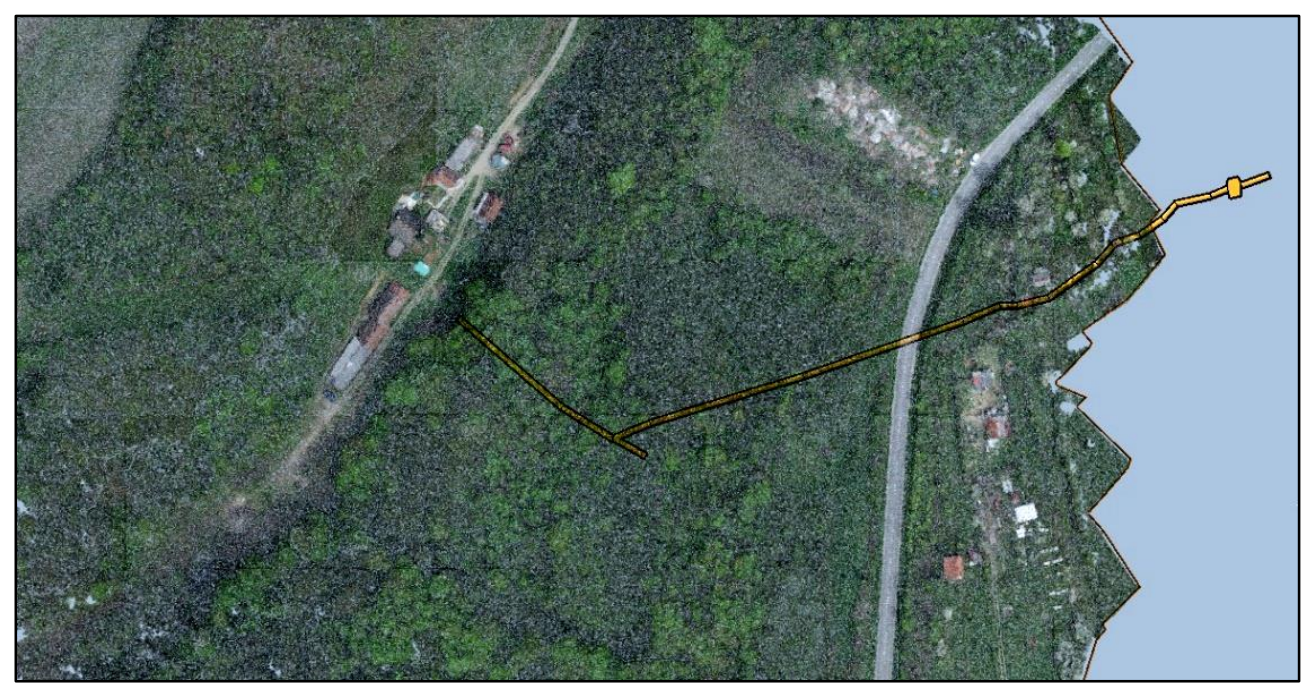

Figure 10 Infrastructure facilities in the zone of influence of underground mining operations

\section{CONCLUSION}

This paper explains the process of creating a 3D model of terrain, digital elevation model and orthophoto, based on the images taken by a digital camera from a UAV. The advantage of using unmanned aerial survey aircraft is reflected in its cost effectiveness, in comparison to traditional aerial photogrammetry, ease of flight control and planning, relatively simple administrative procedures, etc. 3D terrain modeling is done quickly and efficiently using AgiSoft PhotoScan, which is ,user friendly” and allows for the creation of a high-quality terrain model, digital elevation model and orthophoto. Moreover, the AgiSoft PhotoScan, makes it possible to export created models to different formats that are compatible with different types of software for the purpose of further processing.

In the example of the terrain model at the "Crveni Breg" school mine on Avala, the connection of the polygon points of traverse, with the 3D model of the terrain, is shown. A three-dimensional display of underground facilities -in combination with the model of the terrain- enables better perception of the potential impact of underground facilities on surface objects. In the design stage, a 3D display preview can be of great importance in calculating the model of the deposit, the projected facilities and the terrain as well as the loss of useful mineral resources (the cubature that would remain in the protective pillars of objects). Furthermore, it is easier to notice other variants of the mine's opening or the excavation method to use. Additionally, in such integrated 3D terrain and underground mining facilities models, based on safety angles, it is much easier and clearer to define terrain surfaces that will be found in the zone of influence of underground mining operations, as well as the definition of the natural and artificial 
structures in that zone. Infringement of the stability of infrastructural objects can lead to their deformation and damage, loss of function, and even human casualties. Watercourses and other water surfaces, located in the zone of influence of underground mining operations, pose a great potential danger to the mine and miners themselves. Therefore, the regular updating of 3D models of newly- constructed mines, the undertaking of appropriate procedures and the periodical creation of 3D terrain models -based on digital aerial photogrammetry- will help miners to detect the possible development of terrain subsidence and the deformation of objects, as well as protect the miners from the possible occurrence of cracks -and other risks or hazards- that develop on the surface of the terrain as a result of mining activities.

Geodesy and Mine Surveying is, today, increasingly based on instrumentation and measurement methods that ensure the collection of a georeferenced point cloud. It would have been much more efficient if the 3D model of underground mining facilities was acquired based on the 3D images obtained by laser scanners rather than the generalization of rooms based on the coordinates of polygon points of traverse -as was done in this paper. The 3D model thus obtained can have great engineering applications: in examining the efficiency of drilling and mining operations, monitoring the formation and development of deformations in a rock mass, from which it is possible to define the influence of mining operations on the contours of the underground facilities, the condition and efficiency of support systems, timely detection of hazards, as well as for tourist purposes (i.e. creating digital tours in mines with underground exploitation).

\section{REFERENCES}

AGISOFT LLC (2018) Metashape - photogrammetric processing of digital images and 3D spatial data generation. [Online] Available from: http://www.agisoft.com// [Accessed 19/12/2018].

AUTODESK (2018) AutoCad Civil 3D. [Online] Available from: https://www. autodesk.com/products/civil-3d/overview [Accessed 19/12/2018].

CHEN, J. and CLARKE, K. C. (2016) Rapid 3D Modeling Using Photogrammetry Applied to Google Earth. In: Proceedings, AutoCarto2016. The 19th International Research Symposium on Computer-based Cartography, Albuquerque, New Mexico, USA.

CRNOGORAC, L. (2016) Mining Activities Through History At Avala Locality, Podzemni radovi, 28, pp. 61-67.

DIREKTORAT CIVILNOG VAZDUHOPLOVSTVA REPUBLIKE SRBIJE (2015). Pravilnik o bespilotnim vazduhoplovima. [Online] Available from: http://cad.gov.rs/upload /regulativa/Pravilnik\%20o\%20bespilotnim\%20vazduhoplovima\%20(S1\%20glasnik\%20RS, \%20broj\%20108-15).pdf [Accessed 19/9/2018]. 
FIVEADVENTURES (2016) Can you believe it? DJI launch a new drone 'Phantom 4 Pro (\& Pro Plus)' $-A$ comparison with others. [Online] Available from: https://fiveadventurers.com/Home/new-dji-phantom-4-pro/ [Accessed 19/9/2018].

GANIĆ, A. (2011) Geodezija sa rudarskim merenjima. Beograd: Rudarsko-geološki fakultet.

GERKE, M. (2018) Developments in UAV-Photogrammetry. Journal of Digital Landscape Architecture, 3-2018, pp.262-272.

GOJKOVIĆ, Z., RADOJIČIĆ M. and VULOVIĆ, N. (2017) Application For Coordinate Transfomation Between Gaus - Kruger Projection - Bessel Ellipsoid And Utm Projection Wgs84 Ellipsoid. Podzemni radovi, 30, pp. 29-45.

GOOGLE MAPS (2018) Google maps. [Online] Available from: https://www.google. com/maps/ [Accessed 19/12/2018].

GRADSKA OPŠTINA VOŽDOVAC (2018) Opsti podaci. [Online] Available from: https://vozdovac.rs/opsti-podaci/[Accessed 19/9/2018].

KOVANIČ, L. et al. (2017) Surveying of Open Pit Mine Using Low-Cost Aerial Photogrammetry. In: The Rise of Big Spatial Data (pp. 121-129). Springer, Cham.

MIKHAIL, E. M., BETHEL, J. S., and MCGLONE, J. C. (2001). Introduction to Modern Photogrammetry. New York: Chichester: Wiley.

VASSENA, G. and CLERICI, A. (2018) Open Pit Mine 3d Mapping by Tls and Digital Photogrammetry: 3d Model Update Thanks to a Slam Based Approach. In: The International Archives of the Photogrammetry, Remote Sensing and Spatial Information Sciences, Volume XLII-2, 2018 ISPRS TC II Mid-term Symposium "Towards Photogrammetry 2020, " 4-7 June 2018, Riva del Garda, Italy.

RCSHOP (2018) [Online] Available from: https://rcshop.rs/proizvod/dji-phantom-4-proobsidian/ [Accessed 19/9/2018].

SLUŽBENI GLASNIK (2015) Službeni glasnik Republike Srbije broj 108/2015. [Online] Available from: https://www.paragraf.rs/glasila/rs/sluzbeni-glasnik-republike-srbije-1082015.html [Accessed 19/9/2018].

SZ DHU TECHNOLOGY CO. LTD. (2018) [Online] Available from: https://www.dji. com/phantom-4-pro [Accessed 19/9/2018].

TUNG, W.Y., NAGENDRAN, S. K. and ISMAIL M.A.M. (2018) 3D rock slope data acquisition by photogrammetry approach and extraction of geological planes using Facet plugin in Cloudcompare. In: IOP Conf. Series: Earth and Environmental Science 169. 